\title{
ANALYSIS OF OWNER DRIVEN APPROACH OF HOUSING RECONSTRUCTION AFTER GORKHA EARTHQUAKE 2015: A CASE STUDY OF DHUNIBESHI MUNICIPALITY, DHADING
}

Sunil Adhikari ${ }^{\text {a*, Santosh Kumar Shrestha }}{ }^{\text {a }}$, Samyam Aryal ${ }^{\mathrm{b}}$, Roshika Bhattarai $^{\mathrm{a}}$

${ }^{a}$ Department of Civil Engineering, Pulchowk Campus, Tribhuwan University, Lalitpur, Nepal;

${ }^{b}$ School of Public Health, SRMIST, Tamil Nadu, India;

*Correspondence Email: 31sunil.adhikari@gmail.com

the paper is a non-peer reviewed preprint submitted to EarthArXiv 


\title{
ANALYSIS OF OWNER DRIVEN APPROACH OF HOUSING RECONSTRUCTION AFTER GORKHA EARTHQUAKE 2015: A CASE STUDY OF DHUNIBESHI MUNICIPALITY, DHADING
}

\begin{abstract}
A 7.6 magnitude earthquake occurred in Gorkha district of Nepal leading more than 9,000 estimated casualties, approximately 23,000 injuries and damages on more than half a million structures. For leading and managing the earthquake recovery and reconstruction in Nepal, a legally mandated agency named National Reconstruction Authority (NRA) was established in December 2015 which facilitate and oversee reconstruction, using an owner-driven reconstruction model. This research aims to critically analyze the Owner Driven Approach of housing reconstruction followed by Government of Nepal (GoN) for private housing reconstruction after Gorkha Earthquake 2015. A set of parameters was identified, to assess fundamental requirements of Owner Driven Reconstruction (ODR) approach and to analyze beneficiaries' satisfaction, through literature review and expert consultation. A questionnaire survey was used in order to facilitate the collection of information on a sample of 250 beneficiaries and 16 professionals within Dhunibeshi Municipality, Dhading sampled using Proportionate Stratified Random sampling technique. The fulfilment of fundamental requirements of ODR approach was partially validated from both professional and beneficiaries' perception. Further, the results corroborate the success of reconstruction approach with respect to beneficiaries' satisfaction.
\end{abstract}

Keywords: Gorkha earthquake 2015; owner driven reconstruction approach; Nepal; Dhunibeshi municipality

\section{INTRODUCTION}

On Saturday, 25 April 2015, a 7.6 magnitude earthquake occurred in Gorkha district, approximately $76 \mathrm{~km}$ northwest of Kathmandu. There were more than 9,000 estimated casualties and approximately 23,000 injuries. 31 of the country's 75 districts were affected, with 14 severely affected. More than half a million structures were damaged or destroyed, displacing hundreds of thousands of families. [1] 
The National Reconstruction Authority (NRA), established in December 2015, is the legally mandated agency for leading and managing the earthquake recovery and reconstruction in Nepal [2]. NRA facilitates and oversees reconstruction, using an owner-driven reconstruction model which has been used in contexts such as Gujarat, India after the 2001 earthquake, and in Pakistan after the 2005 earthquake.

Owner-driven reconstruction (ODR) models center homeowners in the re-building process by giving reconstruction aid directly to owner vs contracting with intermediaries in the private sector to rebuild homes [3]. Most ODR mechanisms rely on multi-disbursement financing - where the government funds/grants are provided to residents in staggered installments - to ensure code compliant reconstruction in each phase, reducing vulnerability to future earthquakes. In theory, ODR models can also minimize displacement by allowing homeowners to rebuild on the sites of their existing homes. [4]

During post disaster reconstruction, the main challenge lies in designing and implementing location-specific reconstruction programmes which promote locally-available materials and build on existing knowledge, skills and institution. Thus, different studies have indicated the need for effective participation by beneficiary communities in meeting these objectives [5]. The participation of these affected beneficiaries in reconstruction is addressed in ODR approach. In an ODR program, people who lost their shelter are given some combination of cash, vouchers, and in-kind and technical assistance (TA) to repair or rebuild their houses. They may undertake the construction or repair work by themselves, by employing family labour, by employing a local contractor or local laborers, or by using some combination of these options. [6]

The prioritization of needs and the decision-making are in the hands of the affected families, giving them ownership of their project. Owner driven does not imply that the affected family should provide construction labour but it requires that they manage the reconstruction 
with technical assistance. Owner driven projects are defined by three fundamental requirements:

(1) participatory process of decision-making,

(2) adequate technical support, and

(3) adequate financial assistance.

Source: (Global Shelter Cluster (2018))

The success of ODR can be justified by the claim made by state government of Gujarat, to have rebuilt over 200,000 houses and repaired over 900,000 houses, making this the world's largest and fastest reconstruction program (Price and Bhatt 2009, p. 9).

Despite the potential benefits of owner-driven programs, the reconstruction program in Nepal faces many challenges. As of September 2018, three years after devastating Gorkha Earthquake, thousands of affected households remain homeless and unable to rebuild. Of the $8,10,690$ households initially eligible for the program only $4,69,448$ households have received their second installment, and an even smaller 2,58,599 beneficiaries have received their 3rd installment. (GoN, NRA). Being specific to Dhunibeshi Municipality, out of 7158 initial potential beneficiaries only 3875 have received second installment and 2193 received third installment till f/y 2074/075 (source: local authority). Deadline for receival of housing reconstruction grant has consequently been extended time and again. A recent meeting of NRA held on $17^{\text {th }}$ January, 2019 extended time frame for the third time. (GoN, NRA) The abovementioned issues from different literatures justifies the necessity of research to understand the progress of reconstruction using ODR model in Nepalese context. 


\section{RESEARCH METHODOLOGY}

\section{Research Aim}

- To assess the fulfillment of fundamental requirements of owner driven approach in housing reconstruction.

- To analyze the success of owner driven reconstruction approach with respect to satisfaction level of beneficiaries

\section{Research Design}

The aim of research was achieved through quantitative research method using questionnaire survey with

1. Beneficiaries of affected municipality

2. NRA Officials (Engineers, Sub-Engineers, \& Asst. Sub-Engineers) working on same municipality

\section{Non-governmental organization assisting}

To achieve first objective, a draft questionnaire containing 3 fundamental requirements of ODR approach consisting 12 question (4 on each factor) was prepared and later validated through expert review and pre- testing on 30 beneficiaries. The preference of respondents was noted on five-point Likert scale (1= Strongly Disagree, $2=$ Disagree, $3=$ Neither Agree nor Disagree, $4=$ Agree and 5= Strongly Agree) .

In order to achieve second objective, beneficiaries were asked to rank their satisfaction level on five-point Likert scale (1= Strongly Dissatisfied, 2= Dissatisfied, $3=$ Neither Satisfied nor Dissatisfied, 4= Satisfied and 5= Strongly Satisfied) on 9 satisfaction parameters prepared with reference to Karunasena G. and Rameezdeen R. (2015). 


\section{Sample Size Calculation}

Sample Size: Using Cochran (1977)

$$
\frac{\frac{z^{2} \times p(1-p)}{e^{2}}}{1+\left(\frac{z^{2} \times p(1-p)}{e^{2} N}\right)}
$$

Where,

Confidence Level $=90 \%$

Z-Score for $90 \%$ confidence level $=1.65$

Population size $(\mathrm{N}) \quad=2984$

Margin of error (e) $\quad=5 \%$

$\mathrm{p} \quad=0.5$

Sample size $\quad=\underline{\mathbf{2 5 0}}$

Population size $(\mathrm{N})$ seem to be dynamic in nature. Above mentioned value for $\mathrm{N}$ suggests the number of beneficiaries to receive final grant by the end of Magh, 2075 (January, 2019). Source: (GoN, NRA)

Also, to address professionals' perception a list of 16 professional (total population) working on reconstruction within Dhunbeshi Municiplaity was chosen.

For selection of sample, Proportionate Stratified Random sampling was done, i.e. the population itself was split into group of 9 wards and sampling was done proportionately as represented in table 1 . And, the beneficiaries from each ward was then chosen randomly.

However, to encounter worst scenario a set of 300 questionnaires (20\% extra) was distributed and $80 \%$ responds, i.e. 250 responds were collected. 


\section{RESULTS AND DISCUSSIONS}

The collected data from 250 beneficiaries and 16 professionals within Dhunibeshi Municipality was further anlysed using "IBM SPSS Statistics 25.0".

This section of report interprets the core results supposed to be identified by the research. As specified previously, the research aims to critically analyze the Owner Driven Approach of housing reconstruction, further specific analysis for each objective is done based upon collected data. And, thus obtained statistically verified results and findings are represented below.

\section{Objective 1: To assess the fulfilment of fundamental requirements of owner driven approach of housing reconstruction.}

Prior to assessment of fundamental requirements, the internal consistency of data on Likert's scale is scrutinized using Cronbachs' alpha represented in table 2.

Anderson H.J et al. (2006) suggests that Cronbach's alpha greater than 0.6 is acceptable for newly developed questionnaire thus internal consistency of each fundamental requirements of owner driven approach is validated. Further, table 3 represents the test results of independent sample $\mathrm{t}$ test for comparison of means between professionals and beneficiaries' perception on fulfilment of fundamental requirements of owner driven approach of housing reconstruction.

Since, $p$ value from Levene's test is $>0.05$ (not significant) for all three cases null hypothesis "equal variance assumed" can be accepted and further test results of independent sample $\mathrm{t}$ test can be interpreted.

$\mathrm{P}$-value for t-test is $<0.05$ for case 1, i.e. null hypothesis "equality in mean" is rejected. Thus, mean=4.24 suggests that beneficiaries "Agree" about participatory process of decision making while mean=3.52 suggests professional perception in between "Neither agree and disagree" and "Agree". Similarly, P-value for t-test is $<0.05$ for case 2, i.e. null hypothesis "equality in mean" is rejected. Thus, mean=4.31 suggests that beneficiaries' perception in 
between "Agree" and "Strongly Agree" while mean=4.00 suggests professional perception as "Agree" about adequate technical support.

Unlike, in above two cases, P-value for t-test is $>0.05$ for case 3 , i.e. null hypothesis "equality in mean" is accepted. Thus, mean $=3.57$ on beneficiaries and mean $=3.23$ on professionals suggests common perception in between "Neither agree nor disagree" and "Agree.

\section{Objective 2: To analyze the success of owner driven reconstruction approach with respect to satisfaction level of beneficiaries.}

Satisfaction Level (Score) of beneficiaries on different parameters are averaged out of 5 and ranked accordingly, as tabulated in table 4 below.

The satisfaction level is minimum on Response Time of total reconstruction $(\mathrm{m}=3.50)$, i.e. in between "Neither satisfied nor dissatisfied" and "Satisfied". And, maximum on Durability of building $(m=4.36)$, i.e. in between "Satisfied and Strongly satisfied". The mean satisfaction level 4.03 suggests beneficiaries are "Satisfied".

Out of 16 professional respondents, 15 of them accepted that satisfaction level of beneficiaries can be one of the parameters to decide success of housing reconstruction and 11 of them marked "Satisfied" as cut off point. Thus, the mean satisfaction above $4.0(\mathrm{~m}=4.03$ in research) can be concluded as the success of housing reconstruction with respect to satisfaction level of beneficiaries.

Further, to analyze relation between fundamental requirements of ODR approach and Satisfaction Level of beneficiaries a hypothesis was assumed that "Each fundamental requirement has positive impact on Satisfaction level of beneficiaries."

To understand the relation first of all, correlation between Fundamental Requirements and Satisfaction Level was analyzed which is represented in table 5. 
Taylor (1990) suggests if magnitude of correlation is in between 0.9 to 1.0 represents very high correlation, 0.68 to 0.89 represents high correlation, 0.36 to 0.67 represents moderate correlation, and below 0.35 low or weak correlation.

There is moderate but significant correlation of "Participatory process of decision making" and "Adequate Financial support" with Satisfaction Level whereas "Adequate Technical Support" shows low correlation.

In order to investigate the detail relation, further regression analysis was conducted represented in table 6 , which results $\mathrm{R}$-square of 0.38 (moderate), i.e. $38 \%$ variation in dependent variable is explained by independent variable.

VIF (Variation Inflation Factor) value in each case lies nearer to 1, suggests no multicollinearity effects exist

As per assumed hypothesis, Participatory process of decision making $(\beta=0.45, \mathrm{t}=7.45$, $\mathrm{p}=0.000)$ and Adequate financial Support $(\beta=0.27, \mathrm{t}=5.06, \mathrm{p}=0.000)$ shows significant positive relationship with Satisfaction Level.

But, Adequate Technical Support $(\boldsymbol{\beta}=\mathbf{0 . 0 7}, \mathbf{t}=\mathbf{1 . 2 0}, \mathbf{p}=\mathbf{0 . 2 3 3})$ doesn't show any strong and significant relationship with Satisfaction level.

\section{CONCLUSIONS AND RECOMMENDATIONS}

\section{Conclusions}

This research attempted to examine the ODR approach followed by NRA in private housing reconstruction of earthquake affected areas. The fulfilment of fundamental requirements of ODR approach was partially validated from beneficiaries' perception. They agreed about their participation in decision making process, and availability of adequate technical support but remained neutral about adequate financial support. Unlike beneficiaries, professionals remained neutral about public participation in decision making process as well. Further, aim of 
research to analyze the success of ODR approach was justified with respect to satisfaction level of beneficiaries. Beside primary objectives, unanticipated facts about relation between fundamental requirements of ODR approach with Satisfaction level of beneficiaries was explored. The factors, participation in decision making process and adequate financial support, showed significant positive relation with satisfaction level.

\section{Recommendations for concerned stakeholders}

The findings from the study seems to be to fruitful to judge the achievement of national reconstruction project after Gorkha Earthquake 2015. Thus, I strongly recommend NRA and other donor agencies to conduct similar study in large scale throughout earthquake affected regions to critically analyze the reconstruction. Since, the research shows incompetence of government in providing adequate financial support, government should take some action against this issue. Also, necessity of adequate preparedness is felt if similar disastrous situation arises in coming future.

\section{Recommendations for further research}

The limitations of this research can show a pathway for upcoming research. As its' previously mentioned that this research is constrained within a municipality, further approach towards whole vulnerable area can lead to a complete image of owner driven approach of housing reconstruction. Comparative study relating owner driven reconstruction approach with other reconstruction approaches followed within or outside the nation can be another important topic of study. Further, analyzing the success of ODR approach with respect to different parameters unlike only satisfaction parameter considered in this study can result a competitive research. 


\section{ACKNOWLEGEMENT}

I would like to express my deep gratitude to my supervisor Asst. Prof. Santosh Kumar Shrestha, Department of Civil Engineering, Pulchowk Campus, Lalitpur, Nepal for his guidance and support in the preparation of the research.

I would also like to acknowledge all experts (especially Sr.D.E. Yekraj Adhikari) who guided me during questionnaire preparation. I am thankful to Er. Shuvanjan Dahal who supported me in every stage of my research. My special gratitude to all of my respondents, my friends and family who assisted me directly or indirectly during this research period.

Sunil Adhikari 


\section{REFERENCES}

[1] World Bank (n.d.). Nepal Earthquake Post Disaster Needs Assesment. Retrieved from: http://documents.worldbank.org/curated/en/546211467998818313/pdf/97501-WPPUBLICBox391481B-nepal-post-disaster-needs-assement-report-PUBLIC.pdf

[2] Government of Nepal (GoN), National reconstruction Authority (NRA): http://nra.gov.np/np

[3] Owner-Driven Housing Reconstruction Guidelines. International Committee of the Red Cross.

[4] Tafti, \& Mojgan, T. (n.d.). Limitations of the Owner-Driven Model in Post-Disaster Housing Reconstruction in Urban Settlements.

[5] Duyne Barenstein, J. (2006). Housing reconstruction in post-earthquake Gujarat. A comparative analysis. Humanitarian Practice Network. London: Overseas Development Institute. Network Paper, p. 54.

[6] Jha, A.K., Barenstein, J.D., Phelps, P. M., Pittet, D., \& Sena, S. (2010). Safer Homes, Stronger Communities: A Handbookfor Reconstructing after Natural Disasters. World Bank.

[7] Global Shleter Cluster (2018, September 18). Owner Driven Approaches. Retrieved from: https://www.sheltercluster.org/sustainable-solutions-working-group/library/ownerdriven-approaches

[8] Johnson, A.L. (n.d.). Owner Driven Reconstruction: A Model for Nepal. Retrieved from http://abari.earth/odr/

[9] Price, G., Bhatt, M. 2009. The Role of the Affected State in Humanitarian Action: A Case Study on India. Overseas Development Institute (ODI)/ Humanitarian Policy Group (HPG)

[10] Karunasena, G., \& Rameezdeen, R. (2010). Post-disaster housing reconstruction: Comparative study of donor vs owner-driven approaches. International Journal of Disaster Resilience in the Built Environment.

[11] Hair J, Anderson R, Tatham R and Black W. (2006). Multivariate Data Analysis. NJ: Pearson/Prentice Hall, Inc.

[12] Taylor R. (1990). Interpretation of the Correlation Coefficient: A Basic Review. Journal of diagnostic medical sonography. 


\section{APPENDICES}

Table 1: Sample size (Ward wise)

\begin{tabular}{cccc}
\hline Wards of Dhunibeshi Municipality & Population & Sample & \% distribution \\
\hline 1 & 352 & 29 & 11.80 \\
2 & 468 & 39 & 15.69 \\
3 & 428 & 35 & 14.35 \\
4 & 386 & 32 & 12.94 \\
5 & 341 & 29 & 11.43 \\
6 & 218 & 19 & 7.31 \\
7 & 272 & 23 & 9.12 \\
8 & 257 & 22 & 8.62 \\
9 & 262 & 22 & 8.79 \\
Total & $\mathbf{2 9 8 4}$ & $\mathbf{2 5 0}$ & $\mathbf{1 0 0}$ \\
\hline
\end{tabular}


Table 2: Convergent Validity representation

\begin{tabular}{lcc}
\hline \multicolumn{1}{c}{ Fundamental Requirements } & \multicolumn{2}{c}{ Cronbachs' Alpha } \\
\hline & Beneficiaries & Professionals \\
\hline 1. Participation in decision making process & 0.65 & 0.65 \\
2. Adequate Technical Support & 0.68 & 0.70 \\
3. Adequate Financial Support & 0.70 & 0.73 \\
\hline
\end{tabular}


Table 3: Mean score of fundamental requirements

\begin{tabular}{|c|c|c|c|c|c|c|c|c|}
\hline & & & \multicolumn{2}{|c|}{$\begin{array}{l}\text { Levene's Test } \\
\text { for Equality of } \\
\text { Variances }\end{array}$} & \multicolumn{4}{|c|}{ t- test for equality of means } \\
\hline & & $\mathrm{N}$ & $\mathrm{F}$ & Sig. (p) & $\mathrm{t}$ & $\begin{array}{l}\text { Sig. } \\
\text { (p) }\end{array}$ & Mean & S.D. \\
\hline $\begin{array}{l}\text { 1. Participation } \\
\text { in decision } \\
\text { making } \\
\text { process }\end{array}$ & $\begin{array}{l}\text { Beneficiary } \\
\text { Professional }\end{array}$ & $\begin{array}{l}250 \\
16\end{array}$ & 0.04 & 0.83 & 4.97 & 0.000 & $\begin{array}{l}4.24 \\
3.52\end{array}$ & $\begin{array}{l}0.57 \\
0.57\end{array}$ \\
\hline $\begin{array}{l}\text { 2. Adequate } \\
\text { Technical } \\
\text { Support }\end{array}$ & $\begin{array}{l}\text { Beneficiary } \\
\text { Professional }\end{array}$ & $\begin{array}{c}250 \\
16\end{array}$ & 0.01 & 0.91 & 2.12 & 0.035 & $\begin{array}{l}4.31 \\
4.00\end{array}$ & $\begin{array}{l}0.56 \\
0.56\end{array}$ \\
\hline $\begin{array}{l}\text { 3. Adequate } \\
\text { Financial } \\
\text { Support }\end{array}$ & $\begin{array}{l}\text { Beneficiary } \\
\text { Professional }\end{array}$ & $\begin{array}{c}250 \\
16\end{array}$ & 0.21 & 0.64 & 1.68 & 0.093 & $\begin{array}{l}3.57 \\
3.23\end{array}$ & $\begin{array}{l}0.78 \\
0.70\end{array}$ \\
\hline
\end{tabular}


Table 4: Satisfaction Score

\begin{tabular}{lcc}
\hline \multicolumn{1}{c}{ Parameters } & Mean (m) & Standard Deviation \\
\hline 1. Response Time & 3.50 & 1.07 \\
2. Grant Distribution Procedures & 3.64 & 1.02 \\
3. Functionality and Overall Facilities & 3.92 & 0.87 \\
4. Prospective Changes in Future & 3.99 & 0.84 \\
5. Quality of Construction Materials & 4.19 & 0.64 \\
6. Location & 4.20 & 0.78 \\
7. External Appearance/Façade & 4.20 & 0.72 \\
8. Size of Land & 4.29 & 0.68 \\
9. Durability & 4.36 & 0.61 \\
Total Mean & $\underline{\mathbf{4 . 0 3}}$ & \\
\hline
\end{tabular}


Table 5: Correlation between fundamental requirements of ODR approach and satisfaction level

\begin{tabular}{lcccc}
\hline & 1 & 2 & 3 & 4 \\
\hline 1. Participatory process of decision making & 1 & - & - & - \\
2. Adequate Technical Support & $0.51^{* *}$ & 1 & - & - \\
3. Adequate Financial Support & $0.29^{* *}$ & $0.20^{* *}$ & 1 & - \\
4. Satisfaction Level & $0.56^{* *}$ & $0.35^{* *}$ & $0.41^{* *}$ & 1
\end{tabular}

**. Correlation is significant at the 0.01 level (2-tailed).

*. Correlation is significant at the 0.05 level (2-tailed). 
Table 6: Regression Analysis

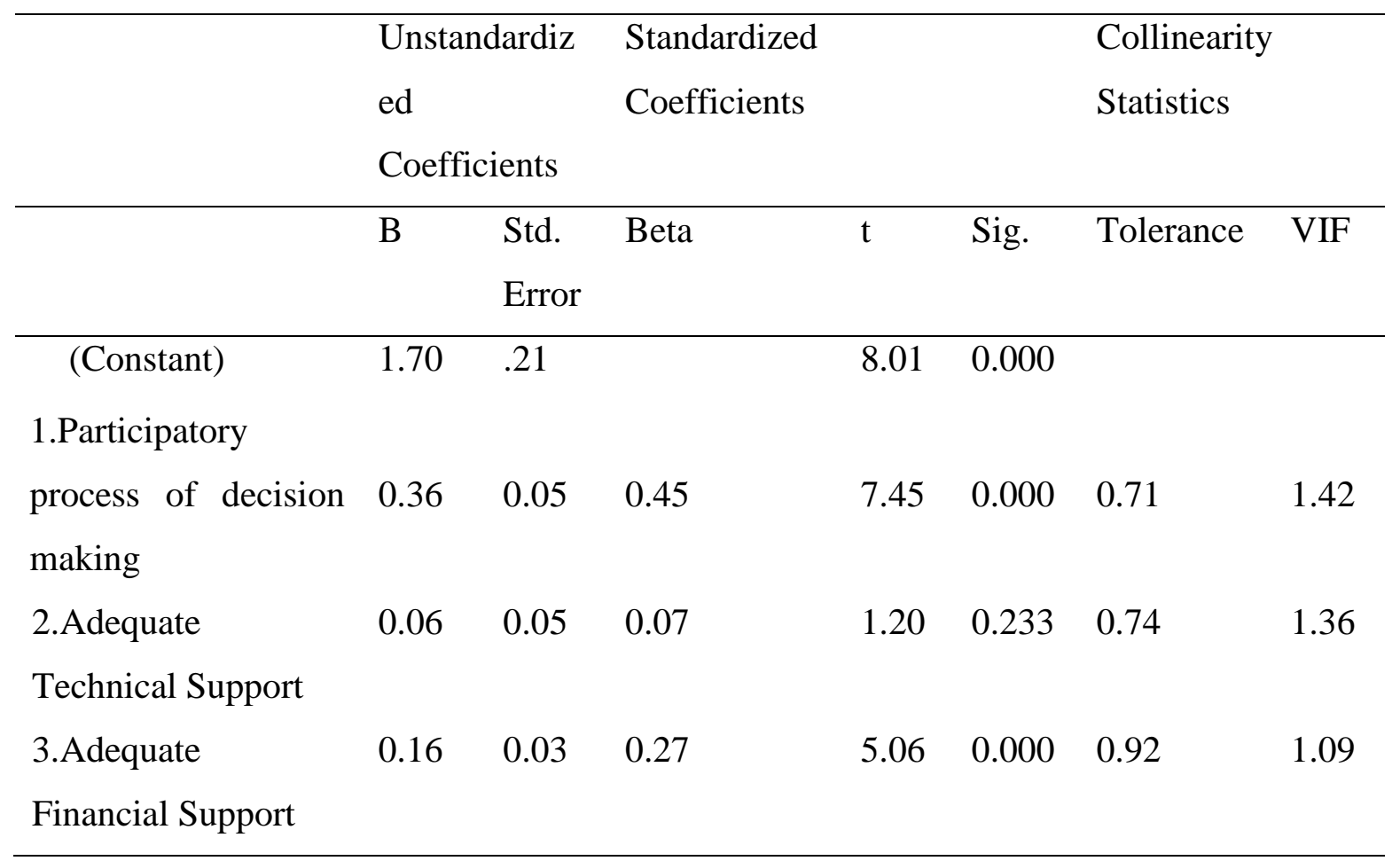

Dependent variable: Satisfaction Level 